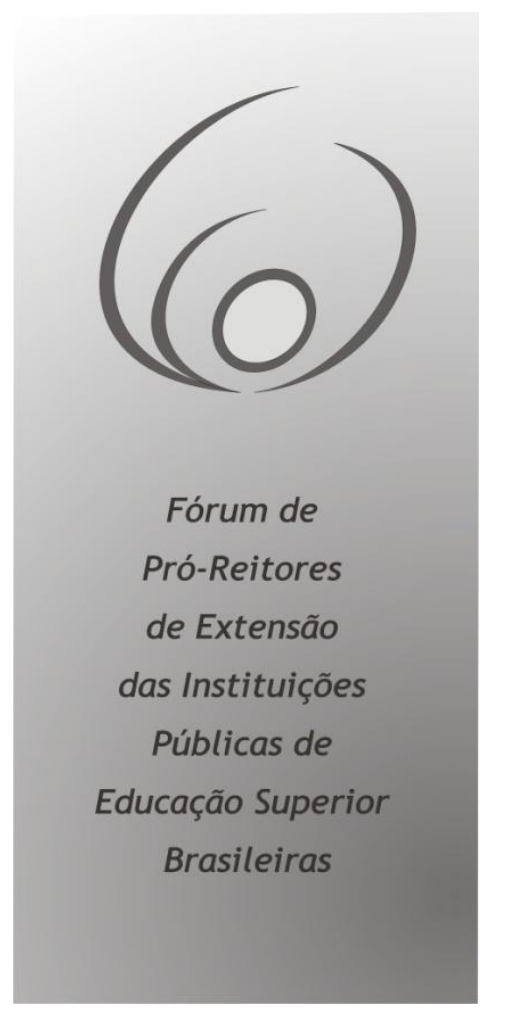

originais recebidos em 28 de abril de 2015

aceito para publicação em 30 de julho de 2015

\title{
A Engenharia na Escola
}

Valéria Pelizzer Casara ${ }^{1}$ Rutyeli Dalla Vecchia ${ }^{2}$, Rosane Rossato Binotto ${ }^{3}$, Rodrigo Rodrigues $^{4}$, Ojanes Daga $^{5}$,
Marcia Bianchi $^{6}$, Rosangela Da Silva ${ }^{7}$, Ana Lucaroni $^{8},{\text { Leda Battestin } \text { Quast }^{9}}^{9}$

Resumo: Este projeto teve por objetivo principal mostrar às jovens do ensino médio, como as áreas de exatas e de engenharia podem estar inseridas em situações rotineiras por elas vivenciadas e incentivá-las para ingressarem nessas áreas. O projeto foi executado na escola de ensino Médio Nelson Horostecki na cidade de Chapecó, Santa Catarina. Mostrou-se de forma simples que as áreas de exatas e de engenharia têm aplicações práticas nas nossas vidas. No desenvolvimento do projeto, realizaram-se oficinas na escola cujo tema principal abordado foi o processo de fabricação do chocolate, visto que o mesmo é um produto muito apreciado pelas adolescentes. Dentro dessa temática, foram trabalhadas as questões que envolvem conhecimentos das áreas de exatas e de engenharia, mais especificamente a Engenharia Ambiental. O projeto auxiliou na formação cidadã e também na escolha profissional das meninas. Muitas das alunas participantes nunca haviam tido contato direto com alunos graduandos de cursos na área das exatas. Mais ainda, este projeto oportunizou a aproximação da universidade com a comunidade externa.

Palavras-chave: Extensão Universitária, Ciências Exatas e Engenharia, Chocolate, Oficinas.

1 Estudante de Engenharia Ambiental, Universidade Federal da Fronteira Sul -UFFS. leia casara@hotmail.com

2 Estudante de Engenharia Ambiental - Universidade Federal da Fronteira Sul - UFFS. rutyeli.dv@gmail.com

3 Professsora Dra., Universidade Federal da Fronteira Sul - UFFS. rosane.binotto@uffs.edu.br

4 Técnico de Laboratório, Universidade Federal da Fronteira Sul - UFFS. rrodrigues@uffs.edu.br

5 Professora de Ensino Médio, Escola de Educação Básica Nelson Horostecki, Av. Porto Alegre, 819N, Centro, Chapecó, SC. CEP $89802-$ 131. ojanesbagiodaga@hotmail.com

6 Professora de Ensino Médio, Escola de Educação Básica Nelson Horostecki. mmarbianchi@uol.com.br

7 Estudante do Ensino Médio, Escola de Educação Básica Nelson Horostecki. Rosangela.1604@hotmail.com.br

8 Estudante do Ensino Médio, Escola de Educação Básica Nelson Horostecki. anislucaroni@gmail.com

9 Professora Dra., Universidade Federal da Fronteira Sul - UFFS, Av. Fernando Machado, 108E, $2^{\circ}$ andar, Centro, Chapecó, SC. CEP $89812-$ 000. leda.quast@uffs.edu.br (autora para correspondência) 


\title{
Engineering in the school
}

\begin{abstract}
The main objective of this project was to show high school female students how the exact sciences and engineering can be included in their routine situations encouraging them to entering in these areas. The project was carried out at the Nelson Horostecki High School in Chapecó, Santa Catarina State, Brazil. It was showed in a simple manner how exact sciences and engineering have practical applications in our lives. Workshops were conducted in the school during the execution of the project in which the main subject was the chocolate manufacturing process, since chocolate is a product greatly appreciated by the young female people. Within this matter, the activities were performed using the knowledge of exact sciences and engineering, and more specifically, Environmental Engineering. The activities assisted in civic education and also in the career choice of the girls. Many of the participating students never had any direct contact with undergraduate students from any course in the area of the exact sciences and this project provided an opportunity to approximate the university and the outside community.
\end{abstract}

Key words: University extension, Exact Science and Engineering, Chocolate, Workshops.

\section{La ingeniería em la escuela}

Resumen: El principal objetivo de este proyecto era mostrar las estudiantes de secundaria cómo las ciencias exactas y la ingeniería se pueden incluir en sus situaciones rutinarias animándoles a entrar en estas áreas. El proyecto se ejecutó en la escuela Nelson Horostecki en la ciudad de Chapecó-SC. Se mostró de una manera sencilla cómo ciencias exactas e ingeniería tienen aplicaciones prácticas en nuestras vidas. Talleres se llevaron a cabo en la escuela durante la ejecución del proyecto en el que el tema principal era el proceso de fabricación del chocolate, ya que el chocolate es un producto muy apreciado por las jóvenes. Dentro de este tema, se trabajaron cuestiones relacionadas con el conocimiento de las ciencias exactas y la ingeniería, específicamente la Ingeniería Ambiental. Las actividades contribuyeran en la educación cívica y también en la elección de carrera de las chicas. Muchas de las chicas estudiantes que participaran nunca habían tenido antes contacto directo con estudiantes de pregrado en cursos del área de las ciencias exactas. Además, este proyecto brindó un acercamiento de la universidad y con la comunidad externa.

Palabras-clave: Extensión Universitaria, Ciencias Exactas y Ingeniería, Chocolate, Conferencias.

\section{Introdução}

O cenário socioeconômico brasileiro e a necessidade de impulsionar o desenvolvimento científico e tecnológico da nação acenam a necessidade de formação de uma grande quantidade de engenheiros capazes de se adaptarem a novos ambientes onde o impacto social, econômico e ambiental de sua atuação é cada vez mais imprescindível. Esta formação não deve ser pautada somente pela demanda do mercado de trabalho, mas também pela compreensão da atuação deste profissional frente aos profundos contrastes sociais e ao dinamismo das mudanças tecnológicas (UFVJM, 2011).

De acordo com o "Relatório apresentado ao Ministério de Estado da Ciência e Tecnologia sobre alguns aspectos da Física brasileira" em agosto de 2002 é dito que: “A Engenharia no Brasil atingiu alto nível em vários campos, como, por exemplo, as Engenharias Civil, Elétrica, Eletrônica, Materiais, Mecânica e Química" (CHAVES et al., 2002).

De acordo com o "Mapa Estratégico da Indústria 20072015” (SISTEMA INDÚSTRIA, 2005), elaborado pelo Fórum Nacional da Indústria, pondera-se que o maior valor agregado de produção provém do conhecimento e, assim, o capital humano passou a ser o bem mais precioso para as empresas, pois esse é capaz de criar novos produtos e processos, além de melhorar os já existentes. Dentro desse contexto, os profissionais de áreas exatas e os engenheiros têm papel fundamental dentro das empresas e na sociedade, pois são eles que devem ter o conhecimento necessário para propor e implementar inovações.

As novas tabulações do Censo do Instituto Brasileiro de Geografia e Estatística (IBGE) referentes a 2010 revelaram que, entre as 20 carreiras universitárias com maior número de recém-formados de 20 a 29 anos, as mulheres só não são maioria em cinco delas: ciência da computação, engenharia civil, outras engenharias, economias e cursos gerais de saúde. No curso de ciência da computação, por exemplo, apenas $22 \%$ são estudantes do sexo feminino. No curso de engenharia civil e de construção, elas são $28 \%$, e no de engenharia e profissões de engenharia (cursos gerais), 30\% (MULHERES SÃO MINORIA EM APENAS CINCO CARREIRAS, 2013).

Em estudo realizado por Vaz et al., (2013), os autores relatam uma experiência de projeto de extensão no qual 
estudantes do ensino médio foram até a universidade para obter conhecimentos sobre as engenharias e computação. Nas atividades desenvolvidas, foram relacionados conceitos básicos de informática, química, matemática, biologia e física. Os estudantes tiverem oportunidade de conhecer metodologias de ponta desenvolvidas na universidade. Nascimento et al., (2015), por meio do programa de educação tutorial (PET), realizaram um trabalho com estudantes de ensino médio de diversas escolas. Um dos objetivos do trabalho foi oferecer aos alunos uma visão sobre ensino superior e o papel do engenheiro na sociedade. No desenvolvimento do projeto, os autores constataram diferenças no nível de informação sobre engenharias entre os estudantes de escolas públicas e privadas, evidenciando a importância de projetos de extensão junto a estudantes de ensino médio.

Gomes et al., (2014) relatam a experiência em projeto de extensão realizado com alunas de ensino médio. Os autores utilizaram métodos estatísticos de maneira lúdica para aplicação em problemas de engenharia. Também, nessa mesma linha, Indrusiak et al., (2014), realizaram um projeto com meninas de ensino médio dentro da temática do curso de engenharia de energias da Unisinos. As alunas participantes tiveram a oportunidade de desenvolver protótipos, fazer montagens de experimentos e levantamento de campo. Os autores observaram que durante o desenvolvimento do projeto, as meninas demonstraram muito interesse e entusiasmo nas atividades desenvolvidas.

Nesse sentido, os objetivos principais deste trabalho foram: despertar nas jovens envolvidas no projeto, o gosto pelo estudo de ciências exatas e de engenharias, com viés na Engenharia Ambiental, e envolver uma escola de ensino médio em um projeto diferenciado, fortalecendo a parceria entre a comunidade $e$ a universidade.

\section{Procedimentos Metodológicos}

O projeto foi desenvolvido por meio de atividades (oficinas), realizadas no colégio Estadual Nelson Horostecki, com a participação de estudantes meninas do segundo e terceiro ano do ensino médio da escola. No decorrer do projeto, houve, em média, uma participação de 40 alunas. Como ponto importante na realização do projeto, a direção da escola apontou positivamente para a inclusão oficial dessas atividades no planejamento do calendário anual de 2014.

Para o desenvolvimento das oficinas na escola, o desafio foi utilizar um tema que fosse comum e que estivesse presente na vida das jovens. De acordo com MenegazAlmeida (2009), a adolescência é uma fase de mudanças significativas que ocorrem nas dimensões biológica, fisiológica, social e psicológica dos jovens. De acordo com dados apresentados pelo autor, o consumo médio mensal de chocolates nos jovens é cerca de $480 \mathrm{~g} /$ adolescente.
Segundo a notícia publicada no Diário do Grande ABC, em 19 de abril de 2011, 70\% dos consumidores brasileiros de chocolate são os jovens entre 12 e 19 anos (MELO, 2011).

Uma vez que o chocolate é um produto que faz parte do dia a dia da maioria das jovens adolescentes, o seu processo de fabricação foi escolhido como tema de fundo para a elaboração dos temas desenvolvidos nas oficinas.

A seguir são apresentadas as metodologias de trabalho para o desenvolvimento das atividades.

\section{Atividade 1: Diagnóstico da percepção das meninas} sobre engenharias e exatas

Para a realização dessa atividade, com a permissão da diretoria da escola, elaborou-se um questionário simples que foi respondido pelas meninas participantes do projeto. $\mathrm{O}$ preenchimento do questionário teve $\mathrm{o}$ acompanhamento da professora bolsista da escola. O objetivo deste questionário foi obter informações da percepção das meninas sobre educação superior, áreas de exatas e engenharias. Os resultados do questionário foram tabulados e avaliados.

\section{Atividade 2: Palestra sobre engenharias}

Essa atividade foi realizada na escola através de metodologia expositiva, que consistiu em uma palestra sobre temas diversos como: as engenharias (com ênfase na Engenharia Ambiental), a atuação do engenheiro no mercado, bem como uma apresentação dos cursos de exatas e engenharias oferecidos pelas universidades da região. Também destacou-se a importância do estudo nas áreas de química, física e matemática, e suas aplicações em qualquer profissão. Essa palestra foi ministrada pela aluna bolsista do curso de Engenharia Ambiental.

\section{Atividade 3: Tem engenharia no chocolate?}

Esta oficina foi desenvolvida em duas etapas: a primeira consistiu em uma palestra sobre a história do chocolate e seu processo de produção. Buscou-se enfatizar os conceitos de engenharia e atuação dos engenheiros nas diferentes etapas de fabricação do chocolate. Na segunda etapa, realizou-se no laboratório da escola, uma parte prática no qual as meninas participantes foram divididas em grupos e realizaram o monitoramento do tempo e temperatura de derretimento de diferentes tipos de chocolate: chocolate branco, chocolate ao leite, chocolate com $53 \%$ de cacau e chocolate com $70 \%$ de cacau. Para a realização dos experimentos, as amostras de chocolate, previamente picadas, foram colocadas em cápsulas de porcelana em um banho térmico seco. $\mathrm{O}$ monitoramento da temperatura foi realizado com o uso de termopares. Os ensaios foram feitos em duplicata. A Figura 1 apresenta uma fotografia do experimento montado para a realização da parte prática de monitoramento no 
derretimento de chocolates. A cada 2 minutos foi anotada a temperatura da areia (banho seco) e do chocolate, até seu completo derretimento. Esse processo durou aproximadamente 30 minutos.

\section{Atividade 4: Tem Engenharia Ambiental na fabricação do chocolate?}

Em um primeiro momento, as bolsistas da escola visitaram o programa Verde Vida, localizado na cidade de Chapecó (SC), com o intuito de conhecer o trajeto do lixo até uma central de reciclagem. Dessa forma, elas socializaram os conhecimentos com as colegas do ensino médio através da palestra "O Caminho da reciclagem". Em um segundo momento, as alunas do curso de Engenharia Ambiental apresentaram uma palestra sobre reciclagem, explicando a simbologia utilizada e a destinação correta de cada tipo de embalagem. Foram abordados temas referentes a relação de massa de embalagem e massa de produto.

Posteriormente, realizou-se no laboratório da escola, uma parte prática no qual as meninas foram divididas em grupos. Cada grupo recebeu um tipo de confeito: M\&M's®, marshmallow, chocolate em barra e uvas passas com chocolate. Para cada tipo de confeito foi distribuída uma embalagem econômica e embalagens menores, de modo que o conteúdo líquido do produto proveniente das embalagens menores era semelhante ao conteúdo líquido proveniente da embalagem econômica. Com a utilização de uma balança analítica, cada grupo verificou a massa das embalagens e a massa dos produtos contidos nela.

\section{Atividade 5: A matemática e os dados experimentais}

Esta atividade foi realizada no laboratório de informática da Universidade Federal da Fronteira Sul. Neste momento, os dados obtidos da atividade 3 (monitoramento do derretimento do chocolate com o tempo) foram plotados no programa Excel® e as curvas foram avaliadas. Adicionalmente, foram feitos alguns gráficos de funções polinomiais e trigonométricas no software Geogebra®.

\section{Atividade 6: Questionário de finalização das atividades}

A aplicação do questionário foi feita com o acompanhamento das professoras com permissão da diretoria da escola. Esse questionário foi respondido por 26 meninas participantes do projeto. O objetivo deste questionário foi avaliar se o desenvolvimento do projeto auxiliou na sua formação acadêmica e cidadã.

\section{Atividade 7: Socialização}

A atividade de socialização ocorreu nas dependências da escola, na qual participaram os alunos do ensino médio, incluindo os meninos. A socialização aconteceu de maneira expositiva onde os envolvidos no projeto tiveram a oportunidade de socializar as experiências obtidas. Durante esta atividade, foi distribuído um folder (elaborado pelas bolsistas da escola) no qual havia um resumo de todas as atividades realizadas.

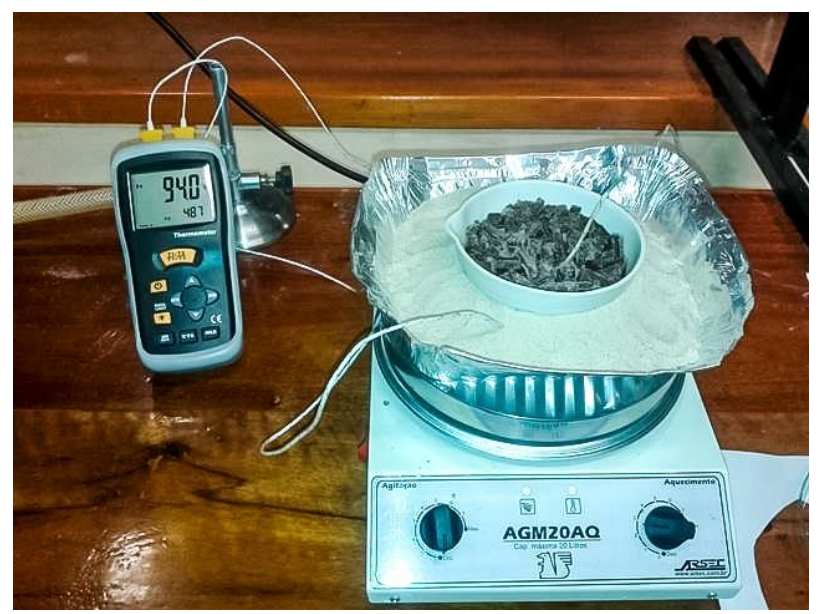

Figura 1. Fotografia demonstrativa da montagem do experimento de monitoramento no derretimento dos chocolates sobre uma chapa aquecedora e monitoramento através de sensor termopar. Fonte: os autores.

\section{Resultados e Discussão}

A seguir, serão apresentados os resultados de cada atividade realizada. As discussões são provenientes de dados técnicos e também das observações e vivências dos membros da equipe e das alunas participantes.

\section{Atividade 1: Diagnóstico da percepção das meninas} sobre engenharias e exatas.

Verificando os dados obtidos na Tabela 1, foi possível observar que 17 alunas entrevistadas (30,4\%) não conhecem algum curso de bacharelado ou licenciatura que envolva as ciências exatas e engenharias. Este dado refletiu-se na segunda pergunta, sendo que das 23 alunas que têm conhecimento das áreas exatas e engenharias, apenas 17 pretendem seguir esta carreira.

A OCDE (Organização para Cooperação e Desenvolvimento Econômico) divulgou o resultado do último PISA (Programme for International Student Assessment), programa que avalia a qualidade da educação em vários países. $\mathrm{O}$ objetivo desse levantamento foi mostrar como as escolas de cada país estão preparando seus jovens para o exercício da cidadania. Nas áreas de matemática, leitura e ciências, o Brasil está abaixo da média dos países da OCDE e a maior parte dos estudantes tem apenas conhecimentos básicos em todas elas. Em matemática, por exemplo, $67 \%$ estão no nível 1 ou inferior, ou seja, são capazes de fazer operações básicas e resolver problemas simples. Apenas $1,1 \%$ dos estudantes está no nível 5 ou 6 , o máximo de proficiência (OCDE, 2005). 
Tabela 1. Respostas obtidas através do questionário da atividade 1 - Diagnóstico da percepção das meninas sobre engenharias e exatas.

\begin{tabular}{lcr}
\hline Perguntas & \multicolumn{2}{c}{ Respostas } \\
\cline { 2 - 3 } & Sim & Não \\
\hline 1- Você conhece alguma engenharia ou área das exatas? & 23 & 17 \\
2- Gostaria de trabalhar na área das engenharias ou exatas? & 17 & 23 \\
3- Você gosta de estudar matemática, química ou física? & 27 & 13 \\
4- Você tem alguma dificuldade no estudo de matemática, química e física? & 37 & 3 \\
5- Em sua família, existe alguém que trabalha na área das engenharias ou na área das & & \\
$\quad$ exatas? & 13 & 27 \\
\hline
\end{tabular}

Fonte: os autores.

A pesquisa da OCDE vai de encontro ao que foi apresentado nas perguntas 3 e 4 da Tabela 1. Das 40 meninas entrevistadas, 27 afirmaram que gostam de estudar matemática, química e física. No entanto, 37 afirmaram ter alguma dificuldade nessas áreas, o que representa $92,5 \%$ das meninas entrevistadas. Este número é alto, mostrando que as dificuldades em matemática, química e física podem levá-las, muitas vezes, a abandonar o estudo dessas disciplinas. De acordo com Selva e Camargo (2009), a matemática tradicionalmente é tida como uma ciência rigorosa, formal e abstrata e, por vezes, dissociada da realidade, o que torna o ensino e a aprendizagem um processo cercado de dificuldades. Diante destes aspectos, os professores buscam priorizar a construção dos conhecimentos, trabalhando em atividades que despertem o interesse e motivação dos alunos.

Em relação à pergunta 5, observa-se que a maioria das meninas não tem familiares que trabalham com engenharias ou áreas exatas. Os familiares são um ponto de apoio em decisões importantes na escolha profissional. Assim, o objetivo das oficinas e palestras realizadas foi apresentar de uma forma simples os vários ramos das Engenharias e suas aplicações.

\section{Atividade 2: Palestra sobre engenharias}

A palestra ministrada referente às engenharias e suas aplicações, teve como base os resultados obtidos do questionário inicial. Após a realização da palestra, foi possível constatar um interesse nas alunas pelo tema que estava sendo abordado. As alunas relataram para as professoras da escola que o assunto sobre engenharias era desconhecido para a maioria delas, e procuraram obter mais informações sobre as áreas de exatas (matemática, química e física) e engenharias. A Figura 2 mostra o registro fotográfico da palestra sobre engenharias realizada nas dependências da escola.

\section{Atividade 3: Oficina: Engenharias e o chocolate}

Na primeira parte da atividade, as alunas da universidade proferiram uma palestra sobre processo de fabricação do chocolate e suas interações com as áreas de engenharias e ciências exatas. O tema chamou muito a atenção das alunas participantes, que mostraram muito interesse em seguir para a aula prática.

$\mathrm{Na}$ parte prática de laboratório, as meninas realizaram o monitoramento da temperatura durante o derretimento do chocolate. A Figura 3 apresenta um registro fotográfico da atividade prática realizada em laboratório.

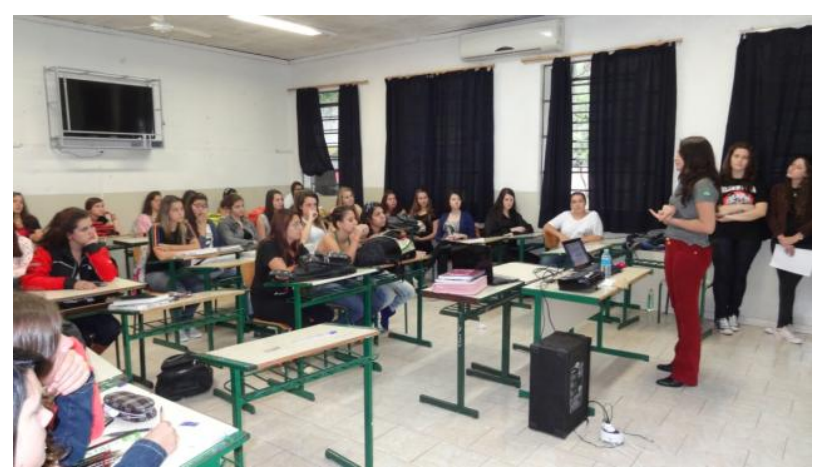

Figura 2. Registro fotográfico da palestra sobre engenharias. Fonte: os autores.

Os resultados numéricos obtidos no monitoramento da temperatura de derretimento dos diferentes tipos de chocolate estão apresentados na Figura 4. Os dados apresentados são a média de duas repetições.

O perfil de derretimento do chocolate pode variar de acordo com a transferência de calor que acontece durante o processo de aquecimento. A transferência de calor, nesse caso em específico, ocorre pelo mecanismo de condução de calor. Esse mecanismo depende, entre outros fatores, da condutividade térmica do material, que por sua vez, depende da composição química do material (BERGMAN et al., 2014). Os diversos mecanismos de transmissão de calor em diferentes materiais fazem parte 
dos conteúdos relacionados aos cursos de exatas e de engenharias.

Avaliando-se os resultados gráficos, observa-se que até cerca de 10 minutos após o início do experimento, a temperatura do chocolate ao leite e do chocolate branco praticamente não sofreu alterações. $\mathrm{O}$ mesmo não aconteceu para os chocolates amargo (com 53 e $70 \%$ de cacau), que iniciaram o processo de derretimento antes. A partir de 16 minutos de experimento, os resultados passam a ter muitas variações. Observa-se que muitos pontos obtidos estão fora da curva. Esse comportamento pode ser justificado pelos seguintes fatores: foi a primeira experiência das alunas com esse tipo de atividade e erros experimentais são naturais, e os termopares possivelmente não estavam bem posicionados, acarretando variações nas medidas.

Vale ressaltar também que cada tipo de chocolate apresenta uma diferente composição. Eles podem variar quanto ao teor de sólidos de cacau, açúcar, sólidos de leite, entre outros ingredientes, contendo, no mínimo, $25 \%$ de sólidos totais de cacau (ANVISA et al., 2005). Assim, dependendo da composição do chocolate, o perfil de derretimento e o ponto de fusão podem variar.

\section{Atividade 4: Tem Engenharia Ambiental na fabricação do chocolate?}

A palestra ministrada pelas bolsistas da escola sobre a experiência da visita na entidade Verde Vida chamou muito a atenção. As meninas participantes da escola tiveram a oportunidade de conhecer o caminho da reciclagem e a sua importância para a vida de muitas pessoas que trabalham nessa atividade. Por outro lado, as meninas da universidade abordaram na palestra os diferentes tipos de materiais e como a sua reciclagem ou a falta dela, altera as condições do meio ambiente. Outra questão bastante discutida pelas participantes da atividade foi a influência dos hábitos de consumo no processo de geração de resíduos.

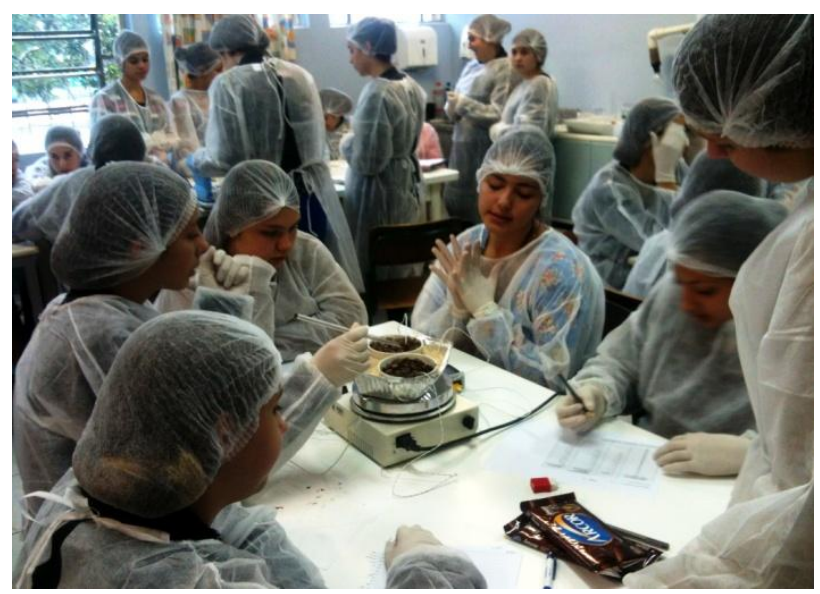

Figura 3. Registro fotográfico da atividade prática de derretimento do chocolate, realizada em laboratório. Fonte: os autores.

A parte prática realizada em laboratório apontou o que foi visto na teoria, ou seja, a geração de resíduo ao se utilizar embalagens econômicas em relação ao uso de embalagens tradicionais.

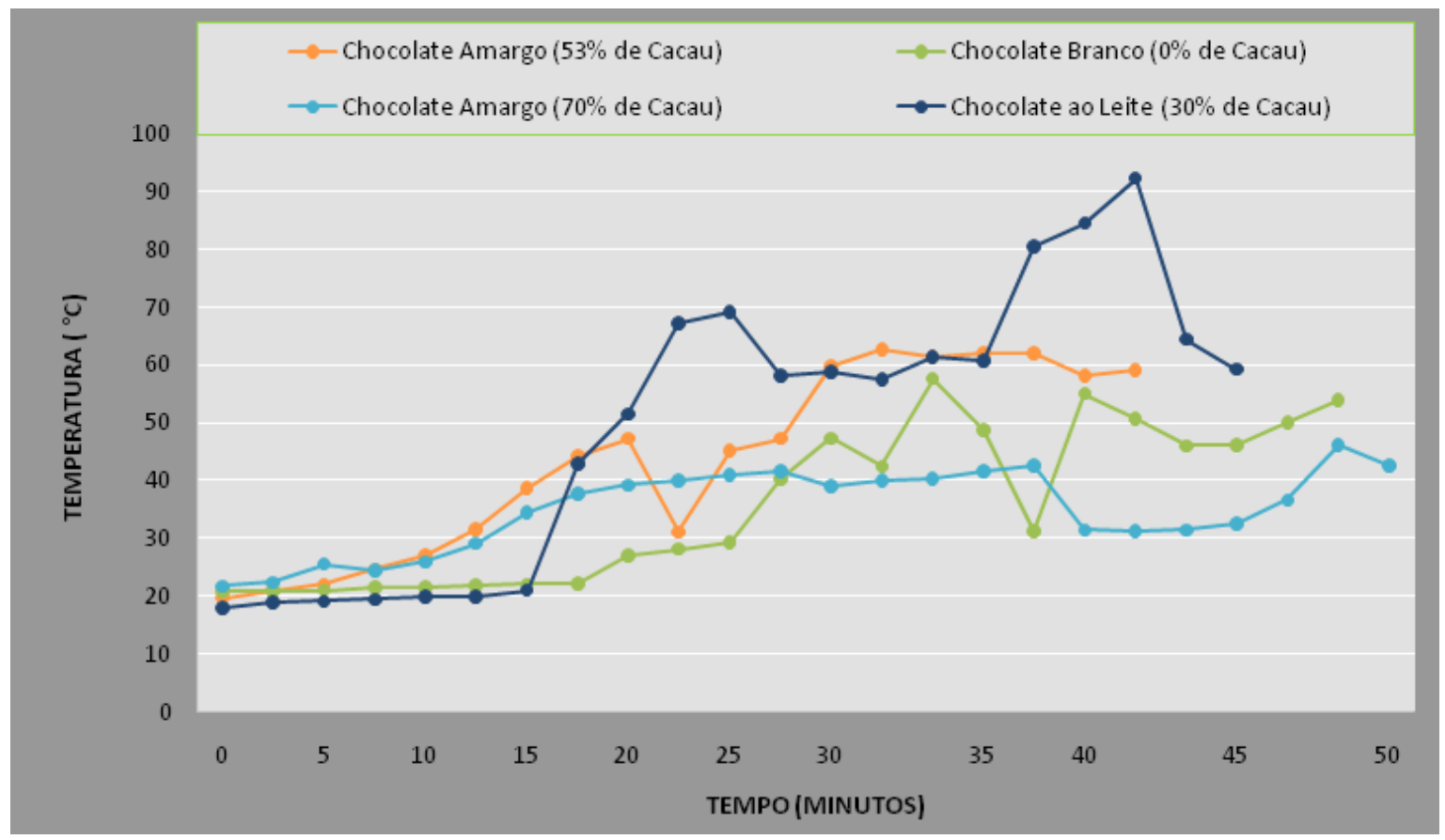

Figura 4. Monitoramento da temperatura de derretimento dos diferentes tipos de chocolate. Os dados apresentados são a média de duas repetições. Fonte: os autores. 
Os resultados obtidos por cada grupo após a medida da massa das embalagens e das massas dos produtos, bem como a relação da massa de produtos pela massa de embalagens, estão mostrados na Tabela 2. Analisando-se os resultados para o chocolate ao leite, observa-se que uma barra que possui $1.004,19 \mathrm{~g}$ de massa de chocolate ao leite, tem $4,32 \mathrm{~g}$ de resíduo gerado pela sua embalagem. Já na união de sete barras do mesmo chocolate de aproximadamente $150 \mathrm{~g}$ cada, somando um total de $1.061,24 \mathrm{~g}$ de massa desse chocolate, e há uma geração de $18,72 \mathrm{~g}$ de resíduo de embalagem. Ou seja, ocorreu uma produção de $62,5 \%$ a mais de lixo, para uma massa de chocolate aproximadamente igual.

Para os demais produtos, foram observados acréscimos na proporção da massa de embalagem de $51,8 \%$ para os M\&M's®, $70 \%$ para as passas de uva coberta de chocolate e $51 \%$ para o marshmallow, quando são utilizadas embalagens individuais.

De acordo com Mucelin e Bellini (2008), é inevitável a geração de lixo nas cidades devido aos hábitos de consumo. Na pesquisa do IBGE (Instituto Brasileiro de Geografia e Estatística) no ano de 2000, apenas 33\% dos municípios coletavam a totalidade dos resíduos domiciliares gerados nas residências urbanas de seus territórios. Os dados do IBGE ainda indicavam que o Brasil produzia 228.413 toneladas diárias de resíduos sólidos, o que equivale a uma produção de $1,2 \mathrm{~kg}$ de resíduo/habitante.As meninas participantes do projeto se surpreenderam com os resultados e com o volume de lixo que geramos, muitas vezes, inconscientemente. Estes resultados apontaram sobre a importância da conscientização dos consumidores desde a hora da compra até o consumo do produto.

\section{Atividade 5: A matemática e os dados experimentais}

Durante a realização dessa atividade com o software Geogebra ${ }^{\circledR}$, as meninas participantes do projeto ficaram impressionadas com as inúmeras maneiras possíveis de se manipular dados obtidos experimentalmente. Foram realizadas atividades que envolviam aplicações de equações e funções matemáticas simples. Assim, ao encerrar a atividade, eles relataram o quanto haviam aprendido em uma única tarde e de maneira dinâmica, utilizando as ferramentas presentes no cotidiano dos adolescentes, como um computador e o software obtido gratuitamente pela internet.

A Figura 5 mostra um registro fotográfico das meninas interagindo no laboratório de informática, utilizando o software Geogebra®.

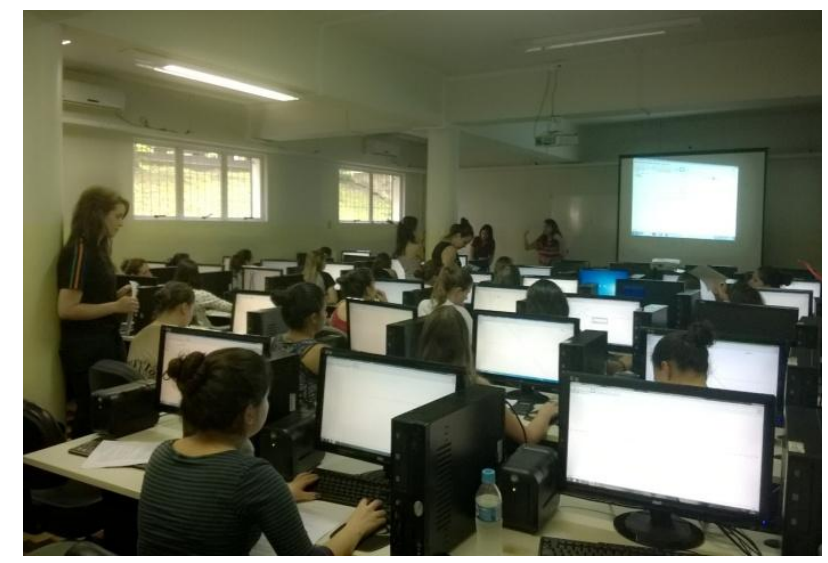

Figura 5. Registro fotográfico da atividade realizada no laboratório de informática utilizando o software Geogebra®. Fonte: os autores.

Tabela 2. Massa de diferentes produtos e suas embalagens, e proporção de massa da embalagem (\%).

\begin{tabular}{|c|c|c|c|}
\hline Produtos & $\begin{array}{l}\text { Massa produto contido } \\
\text { na embalagem }(\mathrm{g})\end{array}$ & $\begin{array}{c}\text { Massa } \\
\text { embalagem }(\mathrm{g})\end{array}$ & $\begin{array}{l}\text { massa embalagem em } \\
\text { relação ao produto (\%) }\end{array}$ \\
\hline \multicolumn{4}{|l|}{ Chocolate ao leite } \\
\hline 1 Embalagem econômica & $1.004,19$ & 4,32 & 0,43 \\
\hline 7 Embalagens individuais & $1.061,24$ & 18,72 & 1,76 \\
\hline \multicolumn{4}{|l|}{ M\&M's® } \\
\hline 1 Embalagem econômica & $1.002,04$ & 9,01 & 0,90 \\
\hline 5 Embalagens individuais & $1.012,53$ & 28,42 & 2,81 \\
\hline \multicolumn{4}{|c|}{ Passas de Uva Cobertas de Chocolate } \\
\hline 1 Embalagem econômica & 505,68 & 3,74 & 0,74 \\
\hline 5 Embalagens individuais & 511,29 & 21,54 & 4,21 \\
\hline \multicolumn{4}{|l|}{ Marsmallow } \\
\hline 1 Embalagem econômica & 507,39 & 12,25 & 2,41 \\
\hline 9 Embalagens individuais & 545,98 & 37,78 & 6,92 \\
\hline
\end{tabular}




\section{Atividade 6: Questionário}

Através das respostas obtidas no questionário destinado a avaliar se o desenvolvimento do projeto auxiliou na sua formação acadêmica e cidadã, observa-se que entre as 26 meninas que o responderam, 18 delas despertaram para a realização de um curso superior (Tabela 3). No entanto, de todas as entrevistadas, apenas oito manifestaram que sentem vontade de estudar engenharia, ciências exatas ou computação. Também ficou evidente que as meninas conseguiram entender os aspectos envolvidos no curso de Engenharia Ambiental, que foi colocado como tema de fundo.

A escolha profissional está muito relacionada com a aptidão individual. Pelos resultados obtidos desse questionário, pode-se levar a pensar que nos cursos de exatas e engenharia ocorrem muitas evasões porque os jovens não conhecem ou têm uma noção restrita do que irão estudar. Quando o jovem ingressa mais consciente sobre o que trata o curso no qual ele está inserido, as chances de concluir o curso com êxito são bem maiores.

Outro aspecto muito importante é que $81 \%$ das meninas (25 respostas) acreditam que os assuntos apresentados durantes as oficinas fizeram com que elas se conscientizassem e tivessem melhores atitudes como cidadãs, repassando os conteúdos e curiosidades para o restante da comunidade. Além disso, metade das meninas mudou sua maneira de pensar em relação à matemática, química e física.

\section{Atividade 7: Socialização}

A atividade de socialização foi um momento importante, pois os demais alunos de ensino médio da escola tiveram a oportunidade de conhecer o que foi realizado no projeto. O folder elaborado com as atividades foi distribuído aos colegas no momento da socialização, o que despertou o interesse e a curiosidade dos participantes.

Faz-se necessário também destacar a importância de projetos de extensão perante a comunidade escolar, visto que, desta forma, é oportunizado o convívio e troca de experiências entre estudantes de ensino médio com universitários, desmistificando alguns fatos acerca do ensino superior.

A Figura 6 apresenta um registro fotográfico da atividade de socialização com os demais colegas de ensino médio da escola. No registro fotográfico, é possível observar que alguns estudantes mostram o folder elaborado pelas alunas.

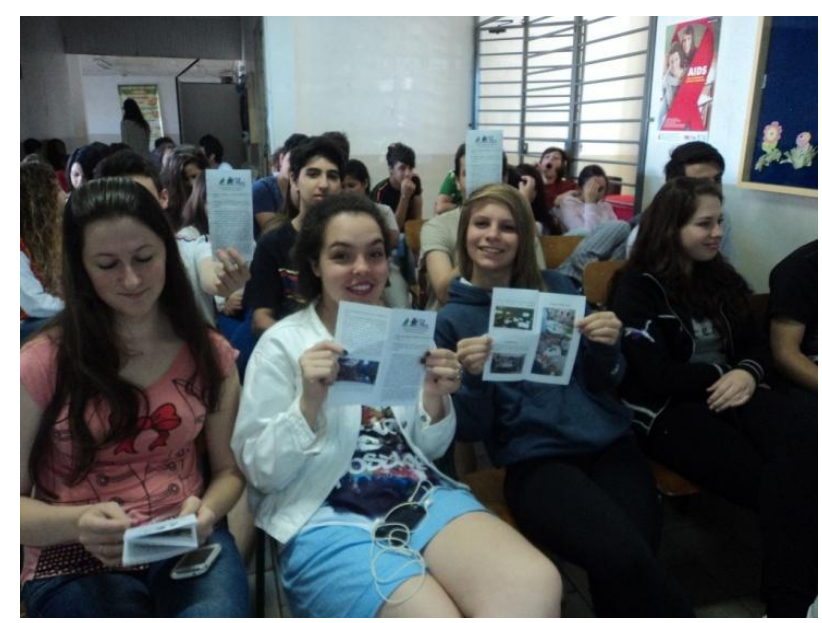

Figura 6. Momento de socialização da atividade com os demais colegas de ensino médio da escola. Fonte: os autores.

Tabela 3. Respostas obtidas através do segundo questionário destinado a avaliar se o desenvolvimento do projeto auxiliou na formação acadêmica e cidadã.

\begin{tabular}{|c|c|c|}
\hline \multirow{2}{*}{ Perguntas } & \multicolumn{2}{|c|}{ Respostas } \\
\hline & Sim & Não \\
\hline $\begin{array}{l}\text { 1- A sua participação no projeto: A engenharia de cada dia levou você a refletir sobre a } \\
\text { sua escolha profissional? }\end{array}$ & 20 & 6 \\
\hline $\begin{array}{l}\text { 2- Os conhecimentos apresentados no decorrer do projeto despertaram em você a } \\
\text { vontade de estudar em um curso de Ciências Exatas, Engenharia ou Computação? }\end{array}$ & 8 & 18 \\
\hline 3- O projeto despertou/aumentou a sua vontade de fazer curso superior: & 18 & 8 \\
\hline 4- Foi possível entender como as coisas funcionam na Engenharia Ambiental? & 25 & 1 \\
\hline $\begin{array}{l}\text { 5- Você acha que os recursos utilizados nas oficinas (conteúdo, didática, } \\
\text { equipamentos,...) foram eficientes para a sua compreensão? }\end{array}$ & 22 & 4 \\
\hline $\begin{array}{l}\text { 6- Os assuntos apresentados durante as oficinas fizeram com que você se conscientizasse } \\
\text { e tivesse melhores atitudes como cidadã? }\end{array}$ & 21 & 5 \\
\hline 7- No decorrer das oficinas, os conteúdos apresentados eram de seu conhecimento? & 11 & 15 \\
\hline $\begin{array}{l}\text { 8- A sua visão sobre a aplicação da física, matemática e química mudou depois da sua } \\
\text { participação do projeto? }\end{array}$ & 13 & 13 \\
\hline
\end{tabular}




\section{Considerações finais}

O grande desafio do atual cenário das Engenharias e Exatas é despertar, ainda no Ensino Fundamental e Médio, o interesse dos jovens sobre as referidas áreas e, diante da oportunidade do Projeto de Extensão aqui apresentado, foi possível realizar atividades que foram ao encontro desse tema.

A Dinâmica utilizada para o desenvolvimento do projeto permitiu uma interação muito grande entre os participantes durante a realização das atividades.

Apesar de que a maioria das jovens participantes não apresentarem interesse em ingressar nas áreas exatas, engenharia ou computação, o projeto auxiliou na reflexão da escolha profissional, bem como na sua formação cidadã.

\section{Agradecimentos}

Ao CNPq e a Petrobrás pelo apoio financeiro do projeto - processo 420247/2013. À Escola de Educação Básica Nelson Horostecki - Chapecó/SC - pelo apoio e parceria nas oficinas.

\section{Referências}

BERGMAN, L.T.; LAVINE, A.S.; INCROPERA, F.P.; DEWITT, D.P. Fundamentos de transferência de calor e de massa. 7 ed. Rio de Janeiro: LTC - Livros técnicos e científicos, 2014.

BRASIL. Agência Nacional de Vigilância Sanitária ANVISA. Resolução - RDC no 264, de 22 de setembro de 2005. Aprova o regulamento técnico para chocolate e produtos de cacau. Diário Oficial da União, n. 184, p. 369. Disponível em: <http://portal.anvisa.gov.br/wps/ wcm/connect/5e63cd804745929d9afede3fbc4c6735/RDC_264 2005.pdf?MOD=AJPERES $>$. Acesso em: 01 mar. 2015.

CHAVES, S.A.; CRUZ, C.H.B.; JORNADA, J.A.H.; ANJOS, J.; LEITE, J.R.; DAVODOVICH, L.; SALMERON, R.; REZENDE, S.M. Relatório apresentado ao ministério da ciência e tecnologia sobre alguns aspectos da física brasileira. 2002.2 Disponível em: $\langle$ http://www.cbpf.br/pdf/RelatorioMCT.pdf $\rangle$. Acesso em: 01 out. 2014.

GOMES, M.M.F.; PESSOA, D.A.; FERNANDES, L.A.; SANTOS, J.C.; VASCONCELOS, A.M.N. Estatística aplicada à engenharia e áreas afins incentivando meninas do ensino médio nas carreiras de ciências exatas, engenharias e computação. In: COBENGE - CONGRESSO BRASILEIRO DE EDUCAÇÃO EM ENGENHARIA, 42, 2014, Juiz de Fora. Anais... Juiz de Fora: ABENGE, 2014.

INDRUSIAK, M.L.S.; CENTENO, F.R.; ZINANI, F.; DIAS, J.B.; LEE, C.Y.Y.; WANDER, P.R. Meninas e jovens fazendo ciências - As propostas da engenharia de energia da Unisinos. In: COBENGE - CONGRESSO BRASILEIRO DE EDUCAÇÃO EM ENGENHARIA. 42, 2014, Juiz de Fora. Anais... Juiz de Fora: ABENGE, 2014.
NASCIMENTO, T.G.V.; PENA, A.C.C.; SILVA, A.C.A.A.; SALES, S.; PÍCOLI, R. A.; FABRINO, D. L. Análise do nível de conhecimento e motivação de alunos do ensino médio rumo ao ensino superior: Projeto Diálogos sobre o que Significa Cursar Engenharia. Revista Brasileira de Extensão Universitária, v.6, n.1, p. 7-13, 2015.

MELO, A. Jovens lideram consumo de chocolate. Diário do Grande ABC. São Paulo, 19 abr. 2011. Disponível em: <http://www.dgabc.com.br/Noticia/134812/jovens-lideramconsumo-de-chocolate>. Acesso em: 18 nov. 2013.

MENEGAZ-ALMEIDA, A. A. Consumo de chocolate, estado nutricional e atividade física e de lazer na adolescência escolar. Mestrado em Fisiopatologia Experimental, Universidade de São Paulo, São Paulo, 2009.

MUCELIN, C.A.; BELLINI, M. Lixo e impactos ambientais perceptíveis no ecossistema urbano. Sociedade $\&$ Natureza, v. 20, n. 1, p.111-124, 2008.

MULHERES SÃO MINORIA EM APENAS CINCO CARREIRAS. Jornal O Globo. 07 jan. 2013. Disponível em: <http://oglobo.globo.com/economia/emprego/mulheres-saominoria-em-apenas-cinco-carreiras-7216998>. Acesso em: 27 fev. 2015.

OCDE. Panorama da Educação nos países da OCDE. 2005. Disponível em: <http://www.oecd.org/education/skills-beyondschool/35333424.pdf $>$. Acesso em: 12 mar. 2015.

SELVA, K.R.; CAMARGO, M. O jogo matemático como recurso para a construção do conhecimento. In: EGEM ENCONTRO GAÚCHO DE EDUCAÇÃO MATEMÁTICA, 10, 2009, Ijuí. Resumos... Ijuí: 2009.

SISTEMA INDÚSTRIA. Mapa Estratégico da Indústria Brasileira 2007-2015: O caminho para o desenvolvimento sustentável. Brasília: Indústria Brasileira, 2005.

UFVJM - UNIVERSIDADE FEDERAL DOS VALES DO JEQUITINHONHA E MUCURI. Projeto pedagógico do curso de Engenharia Mecânica. Diamantina-MG, 2011. Disponível em: </http://webcache.googleusercontent.com/ search?q=cache:Zbfd4T9i7eIJ:www.ufvjm.edu.br/prograd/regu lamento-dos-cursos/doc_download/926-.html+\&cd=1\&hl=ptBR\&ct=clnk\&gl=br $>$. Acesso em: 01 abr. 2015.

VAZ, M.S.M.G.; CHINELATTO, A.S.A.; ALMEDA, M. M.; JÚNIOR, A.S.; VAZ, M.C.S.; CHINELATTO, A.L.; SILVA, N.C.C.; KRUGER, J.A.; FALATE, R.; JÚNIOR, D.C.F. A interação das engenharias e o ensino médio para a melhoria da educação. In: SEURS/ SEMINÁRIO DE EXTENSÃO UNIVERSITÁRIA DA REGIÃO SUL, 31, 2013, Florianópolis. Anais... Florianópolis, UFSC, 2013.

\section{$* * *$}

Como citar este artigo:

Casara, V. P., Dalla Vecchia, R., Binotto, R. R., Rodrigues, R., Daga, O., Bianchi, M., Da Silva, R. Lucaroni, A., Quast, L. B. A engenharia na escola. Revista Brasileira de Extensão Universitária. v. 6, n. 1, p. 43-51, 2015. Disponível em: $<$ https://periodicos.uffs.edu.br/index.php/RBEU/article/view/19 $\underline{49 / p d f}$ 